\title{
Increasing Emotional Intelligence through Self- Reflection Journals: Implications for Occupational Therapy Students as Emerging Clinicians
}

Natalie A. Perkins

Colorado State University

Arlene A. Schmid

Colorado State University

Follow this and additional works at: https://encompass.eku.edu/jote

Part of the Curriculum and Instruction Commons, and the Occupational Therapy Commons

\section{Recommended Citation}

Perkins, N. A., \& Schmid, A. A. (2019). Increasing Emotional Intelligence through Self-Reflection Journals: Implications for Occupational Therapy Students as Emerging Clinicians. Journal of Occupational Therapy Education, 3 (3). https://doi.org/10.26681/ jote.2019.030305 


\title{
Increasing Emotional Intelligence through Self-Reflection Journals: Implications for Occupational Therapy Students as Emerging Clinicians
}

\begin{abstract}
Occupational therapy practitioners and students need skills associated with emotional intelligence (EI) as it is linked with therapeutic use of self. It is vital to train and educate occupational therapy students in selfawareness in order to prepare them to work effectively with future clients and co-workers. This study explored the use of self-reflection journals among graduate students during their spring semester of a full-time oncampus Master's in Occupational Therapy program. Researchers aimed to understand the impact of selfreflection journals on trait EI. First year master level occupational therapy students $(n=39)$ completed the Trait Emotional Intelligence Questionnaire (TEIQue). Quantitative data were gathered from pre/post-test scores. Results indicated that students in the intervention group improved the following trait EI scores: (1) adaptability $(p=.018) ;(2)$ relationships $(p=.021)$. Additional data demonstrated an increase in percent change from pre/post-test among the intervention group as well. The results of this study suggest that even short-term use of self-reflection journals may have the ability to positively influence trait EI skills of future occupational therapy clinicians. Further study of the use of self-reflection journals among occupational therapy students and practitioners are recommended. Researchers provide additional strategies for developing self-awareness skills required for successful occupational therapy practice.
\end{abstract}

\section{Keywords}

Self-awareness, occupational therapy education, online

\section{Creative Commons License}

\section{(a) $\mathbb{Q} \Theta \Theta$}

This work is licensed under a Creative Commons Attribution-Noncommercial-No Derivative Works 4.0 License.

\section{Acknowledgements}

The authors would like to acknowledge the students and faculty at Colorado State University for their participation in this study. The authors would like to thank Karen Duddy, OTD, MHA, OTR/L for her contributions to the development of this study. 


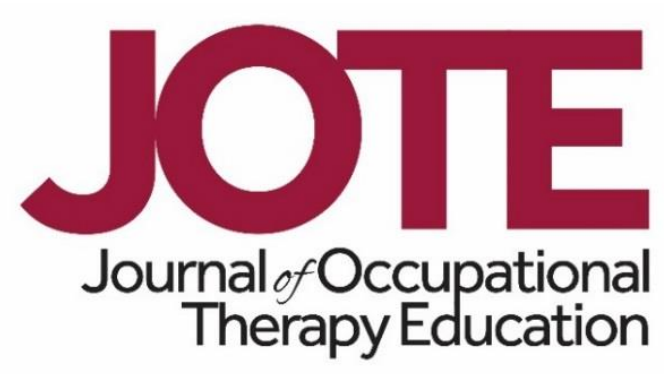

Volume 3, Issue 3

Increasing Emotional Intelligence through Self-Reflection Journals:

Implications for Occupational Therapy Students as Emerging Clinicians

\author{
Natalie A. Perkins, PP-OTD, M.Ed., OTR/L, FIIE \\ Arlene A. Schmid, PhD, OTR, FAOTA \\ Colorado State University \\ United States
}

\begin{abstract}
Occupational therapy practitioners and students need skills associated with emotional intelligence (EI) as it is linked with therapeutic use of self. It is vital to train and educate occupational therapy students in self-awareness in order to prepare them to work effectively with future clients and co-workers. This study explored the use of selfreflection journals among graduate students during their spring semester of a full-time on-campus Master's in Occupational Therapy program. Researchers aimed to understand the impact of self-reflection journals on trait El. First year master level occupational therapy students $(n=39)$ completed the Trait Emotional Intelligence Questionnaire (TEIQue). Quantitative data were gathered from pre/post-test scores. Results indicated that students in the intervention group improved the following trait $\mathrm{EI}$ scores: (1) adaptability ( $p=.018) ;(2)$ relationships $(p=.021)$. Additional data demonstrated an increase in percent change from pre/post-test among the intervention group as well. The results of this study suggest that even short-term use of selfreflection journals may have the ability to positively influence trait El skills of future occupational therapy clinicians. Further study of the use of self-reflection journals among occupational therapy students and practitioners are recommended. Researchers provide additional strategies for developing self-awareness skills required for successful occupational therapy practice.
\end{abstract}

\title{
INTRODUCTION
}

Client satisfaction in healthcare is declining, in part due to the impact of healthcare providers' impaired communication and interaction behaviors (Patterson, 2016).

Evidence shows that ineffective healthcare provider communication skill is associated 
with higher rates of patient complaints; poor health outcomes; increased malpractice claims; and lower levels of patient satisfaction (Kron et al., 2016). Client dissatisfaction with healthcare has a direct impact on reimbursement as clients will seek out services elsewhere when dissatisfied. Self-awareness assists healthcare providers in developing the ability to emotionally connect with clients. Building a connection may increase therapeutic rapport, which is important for successful therapist-client partnerships (Bonvicini et al., 2009). Effective communication and interpersonal skills are built upon self-awareness and are also associated with emotional intelligence (El; Osif, 2010). Emotional intelligence is used to describe how people, such as healthcare professionals, monitor and manage one's own emotional responses and those of others in order to communicate with and relate to others (Andonian, 2017; Carmeli \& Josman, 2006; Mayer, Salovey, \& Caruso, 2008). Effective communication, interpersonal skills, and $\mathrm{El}$ are vital for occupational therapists as well.

Occupational therapists have a unique position in the healthcare world as they are both clinicians and educators. That is, occupational therapists provide clinical interventions as well as educate patients and families on treatment plans, home programs, and emotional well-being (McKenna \& Mellson, 2013). When working with clients and families, occupational therapy practitioners attempt to carefully balance therapeutic hands-on treatment with therapeutic rapport. As clinicians, occupational therapy practitioners have an almost equal impact on the emotional and physical wellbeing of clients and their families, as the relationship between therapists and clients is foundational to successful outcomes (Cole \& McLean, 2003). Moreover, the focus of occupational therapist-client partnerships is often to help the client restore participation in meaningful life activities. However, like all individuals, not all occupational therapists have effective communication skills or abilities that comprise El. Higher El skills have been correlated with greater individual performance in task and relational skills that is above and beyond that which are associated with one's general intelligence (Romanelli, Cain, \& Smith, 2006). Relational skills are an important component of clinical competence for healthcare professionals who have meaningful interactions with clients. To address this, implementation of El programming in the higher education setting has been recommended. Johnson (2015) suggested that El training should be integrated into the professional curriculum and give students opportunities to practice the skills, and not delivered as an additional course. Integrating El training into the occupational therapy curriculum could be both practical and beneficial as it would be an asset to the occupational therapy profession if there was increased awareness of the interplay between El skills and therapeutic use of self in terms of the impact these interpersonal skills have on client outcomes (McKenna \& Mellson, 2013).

Commonly, occupational therapy students are engaged learners seeking knowledge in order to become effective practitioners. Occupational therapy students are taught the fundamental clinical skills as well as the value of therapeutic rapport. Occupational therapists are highly educated in the medical model of service delivery, leading to their in-depth understanding of neurology, biology, and body mechanics. However, therapists' education and training often does not include or focus on scientific insights into emotions and an individual's emotional architecture, which can result in biases or 
miscommunication between the provider and the client (Johnson, 2015). When healthcare providers are unaware of personal biases it may impact the therapeutic relationship (Besika, Collard, \& Coogan, 2018). Occupational therapy students should develop skills that will enable them to succeed during fieldwork. By learning to develop new emotional responses with clients, occupational therapy practitioners and students can become more interpersonally effective. In order to build new communication or interaction skills occupational therapy practitioners and students need to increase selfawareness and apply strategies to improve El.

Despite a growing base of evidence to support the need for El and self-awareness training, there is a limited amount of research on self-awareness and El training for students in occupational therapy programs. As the use of El and self-awareness training within accredited occupational therapy programs becomes more prevalent, it will be important to describe and differentiate the benefits of and barriers to potential types of El training. There is evidence of a gap in the literature related to the degree of $\mathrm{EI}$, and its relationship to occupational therapy students' receiving self-awareness training. Therefore, this study examined the relationship between El and self-awareness training. Specifically, the research questions included: (1) what is the impact of self-awareness training through use of self-reflection journals in improving related trait El skills of master level occupational therapy students? (2) what is the difference in trait El skills related to self-awareness between first- and second-year master level occupational therapy (MOT) students?

\section{LITERATURE REVIEW}

Self-awareness is one of many components under the umbrella of El. Effective communication is built upon self-awareness. Moreover, personal and social skills are associated with El and the ability to be self-aware (Osif, 2010). In a study by Kron et al. (2016) ineffective healthcare provider communication skill was associated with higher rates of patient complaints, poor health outcomes, increase malpractice claims, and lower levels of patient satisfaction. Being self-aware includes being aware of feelings and emotions that may arise during the day. Oftentimes emotions are evoked about a personally sensitive topic. Awareness of non-verbal reactions is another key component of self-awareness. Therapeutic relationships demand a level of honesty and trust between client and healthcare provider. It is imperative that healthcare providers be self-aware in order to prevent a breakdown in trust. Providers need to be cognizant of how their own personal emotions can impact a treatment session. Therapists who are able to personalize responses and who are aware of their communication style are better able to establish rapport (Allen, Montgomery, Tubman, Frazier, \& Escovar, 2003).

Emotional intelligence and its components is a relatively new theory. Research in this area has mainly been based within the field of psychology and the impact of El within large corporations. While there is some research within the medical field and occupational therapy (Andonian, 2013; Carvalho et al., 2011), without an advancement of the evidence within the profession of occupational therapy, there has been little impetus to add specific self-awareness curriculum to occupational therapy programs. Second, there is limited research demonstrating the most effective method for self- 
awareness training. The relationship between these two factors are supported by the assumption that increased self-awareness which is (a component of $\mathrm{El}$ ), will increase $\mathrm{EI}$ skills which in turn will improve therapeutic rapport, communication skills, and collaboration skills.

\section{Theoretical Frameworks}

Two frameworks were used in developing this research project to better understand the foundational components of the identified problem or knowledge gap. This gap is defined as the limited amount of self-awareness training in occupational therapy programs which impacts occupational therapy students as emerging clinicians as well as practicing clinicians. The El theory (MacCann, Joseph, Newman, \& Roberts, 2014) and the Objective Self-awareness (OSA) theory (Duval \& Wicklunds, 1972) were selected to guide the researchers in developing the intervention. These theories emphasize the relationship between self-awareness training and improved overall El.

Emotional intelligence theory. Emotional intelligence is defined as the "ability to process and reason about emotional information and is therefore measured by tasks that require this ability" (MacCann, Joseph, Newman, \& Roberts, 2014, p. 358). Emotional intelligence is comprised of dimensions that include self-awareness and is a competence of perceiving emotions in others and within one's self (Goleman, 2006). In contrast, emotional unintelligent behaviors may have damaging effects to organizations and clients. Self-awareness is a personal competence of recognition in the areas of emotional self-awareness, accurate self-assessment, and self-confidence and $\mathrm{El}$ is important in order to manage emotions and reactions (Zeidner, Matthews, \& Roberts, 2009).

The main focus of the El theory is an examination of the learned skills that may translate into success throughout various social domains, such as the healthcare workplace. Insight into one's own emotional competencies is a core component of selfawareness, improved ability to work with others, and building rapport (Brown, Williams, \& Etherington, 2016).

The Objective Self-awareness theory. Objective Self-Awareness theory (Duval \& Wicklund, 1972) postulates that human consciousness is bidirectional. That is, becoming aware of oneself and behavior results in increased awareness and ability to compare oneself to others and recognize standards of correct behavior. Duval and Wicklund (1972) described standards as "all of the standards of correctness taken together define what a 'correct' person is" (p. 3-4). In other words, the standards of correctness for a professional in the workplace include appropriate attire, professional language, and ability to adjust communication style and represent the company brand. A key principle of OSA theory is comparing personal performance or internal state with external standards.

In summary, the OSA theory (Duval \& Wicklund, 1972) and El theory (Goleman, 2006; Mayer, Salovey, \& Caruso, 2008) provide lenses for examining one's self, the interaction with others, and the transactions between these elements within healthcare 
practice. By understanding the value and impact of self-reflection, occupational therapy students, and emerging clinicians will have the ability to modify personal elements though self-reflective activities. Through self-reflection, one begins to identify areas of strength and need, and can identify emotional responses. The process of reflection may improve personal performance and encourage continued self-awareness over time.

\section{METHODS}

\section{Research Design}

This was a non-equivalent group study design. The experimental group consisted of first-year MOT students who received and completed monthly self-reflection journals during the spring academic semester. In order to evaluate trait El scores, second-year MOT students completed pre and post assessment but did not complete the selfreflection journals and received no additional intervention outside of their standard occupational therapy curriculum.

\section{Participants}

Participants included first and second year MOT students within the Department of Occupational Therapy at Colorado State University. Participants voluntarily participated in the study, which was separate from coursework and activities and therefore, were completed on their own time.

\section{Procedures}

Institutional Review Board approval of the study was received from Colorado State University as an exempt study. First and second year MOT students were contacted and provided an explanation of the study. Students who chose to participate consented to participate in the study. There were no identifiers collected and all participants remained anonymous.

First-year MOT students completed the TEIQue in January 2018 and May 2018 (beginning and end of the semester). First-year MOT study participants received a total of four online self-reflection journals, one journal each month of the spring semester (January, February, March, April). The journals consisted of 3-4 short answer openended questions. Online self-reflection journals were developed for occupational therapy students to use throughout the academic semester. Using the background, theories, and literature reviews, the researchers developed the questions for the selfreflection journals. The following are examples of some of the journal questions:

1. How do your behaviors and actions support what you say and do?

2. Discuss a time when what you said or did had a positive impact on a fellow student or co-worker.

3. Describe how you impact the occupation choices of those around you. Reflect on what was said, how each person responded, and the feelings involved.

4. Discuss a time you were distracted or preoccupied by something. How did you know? What impact did it have on your performance? What impact did it have on others? 
Another component of self-reflection is the ability to recognize emotional responses. Understanding and recognizing how one's emotions impact others is a central component of self-awareness. Positive reflection can lead to learning self-awareness and also facilitate personal accountability. The following are example questions addressing emotional responses:

1. Describe a time when your emotions were triggered by the actions of another.

2. Did you recognize your emotional trigger in the moment or later?

3. How could you respond differently next time?

Second-year MOT students completed the TEIQue in January 2018 and May 2018. These students did not receive the self-reflection journals and received no additional intervention activities outside of the standard second year MOT curriculum.

\section{Instruments}

The TEIQue Full Form (Petrides, 2018) was used to measure trait El and was the dependent variable. The TEIQue is a self-report inventory that is comprised of 153 questions which are rated on a 7-point Likert scale from 1 (strongly disagree) to 7 (strongly agree), and measures 15 distinct facets (Emotion Perception, Trait Empathy, Emotion Expression, Relationships, Emotion Regulation, Stress Management, Impulsiveness, Adaptability, Self-Motivation, Assertiveness, Emotion Management, Social Awareness, Self-Esteem, Trait Happiness, Trait Optimism). These facets were grouped into 4 factors: Well-Being, Self-Control, Emotionality, and Sociability and global trait El (Blanco, Garcia, \& Aluja, 2016). The scores vary between 1 (minimum) and 7 (maximum), with a theoretical average of 3.5. The higher the value, the more likely an individual has strong skills within that El trait. Internal consistency of the TEIQue was measured by Cronbach's alpha coefficient. According to Petrides (2009) Cronbach's alpha coefficient reliability for the scale is usually above 0.80 . Cronbach's alpha total for this construct was 0.80 (pre-test) and 0.85 (post-test) in the current study.

\section{Data Analysis}

Data were entered into, and quantitative data analyses were performed, using SPSS version 25. The changes in the total scores, subscale scores from post assessments were then calculated for each group for targeted traits (first year and second year MOT students). Independent $t$-tests were used to compare pre and post TEIQue facet scores between the two groups (first year and second year MOT students). Alpha was set at 0.05 for significance.

\section{RESULTS}

Approximately 52 first year students received an email with a link to an online selfreflection journal. Those that voluntarily completed the journals $(n=49)$ and those that were also able to be on campus for the pre/post assessment $(n=39)$ were included in the data in Table 2. Second year students who completed the TEIQue pre/post assessment $(n=44)$ facet scores were included in the data in Table 1. Intervention group means, standard deviations (SD), and Cronbach's alphas for the TEIQue facet scores are reported in Table 2. First-year MOT participants who completed the self-reflection journals improved overall scores in 14/15 facet categories (see Table 2). 
Table 1

Pre-post TEIQue Scores for the $2^{\text {nd }}$ Year MOT Students $(n=44)$

\begin{tabular}{lll} 
TEIQue Trait & $\begin{array}{l}\text { Pre- } \\
\text { Assessment }\end{array}$ & $\begin{array}{l}\text { Post- } \\
\text { Assessment }\end{array}$ \\
\hline Self-Esteem & $\frac{\text { Mean }}{5.10}$ & $\frac{\text { Mean }}{5.17}$ \\
Emotion Expression & 4.96 & 5.03 \\
Motivation & 4.86 & 5.03 \\
Emotion Regulation & 4.44 & 4.26 \\
Happiness & 6.07 & 6.02 \\
Empathy & 5.38 & 5.48 \\
Social Awareness & 4.64 & 4.72 \\
Impulse Control & 4.87 & 4.89 \\
Emotion Perception & 4.91 & 4.95 \\
Stress Management & 4.38 & 4.45 \\
Emotion Management & 4.74 & 4.69 \\
Optimism & 5.73 & 5.66 \\
Relationships & 5.69 & 5.62 \\
Adaptability & 4.23 & 4.12 \\
Assertiveness & 4.10 & 4.28 \\
\hline
\end{tabular}


Table 2

Pre-post Intervention TEIQue Scores for the $1^{\text {st }}$ Year MOT Students $(\mathrm{n}=39)$

\begin{tabular}{|c|c|c|c|c|}
\hline TEIQue Trait & $\begin{array}{l}\text { Before } \\
\text { Intervention }\end{array}$ & & $\begin{array}{l}\text { After } \\
\text { Intervention }\end{array}$ & \\
\hline & Mean (SD) & Cronbachs $\alpha$ & Mean (SD) & Cronbachs $\alpha$ \\
\hline Self-Esteem & $5.11(.70)$ & .67 & $5.19(.82)$ & .85 \\
\hline Emotion Expression & $4.93(1.06)$ & .80 & $5.04(.99)$ & .85 \\
\hline Motivation & $4.88(.65)$ & .68 & $5.01(.61)$ & .45 \\
\hline Emotion Regulation & $4.43(.73)$ & .79 & $4.33(.73)$ & .74 \\
\hline Happiness & $6.00(.79)$ & .88 & $5.96(.88)$ & .90 \\
\hline Empathy & $5.42(.67)$ & .55 & $5.52(.63)$ & .63 \\
\hline Social Awareness & $4.65(.80)$ & .72 & $4.75(.76)$ & .74 \\
\hline Impulse Control & $4.79(.83)$ & .66 & $4.92(.85)$ & .74 \\
\hline Emotion Perception & $4.98(.70)$ & .81 & $5.10(.75)$ & .89 \\
\hline Stress Management & $4.36(.91)$ & .79 & $4.48(.85)$ & .77 \\
\hline Emotion Management & $4.68(.77)$ & .65 & $4.70(.70)$ & .37 \\
\hline Optimism & $5.63(.78)$ & .81 & $5.61(.95)$ & .91 \\
\hline Relationships & $5.74(.63)$ & .35 & $5.80(.73)$ & .70 \\
\hline Adaptability & $4.28(.79)$ & .75 & $4.39(.78)$ & .67 \\
\hline Assertiveness & $4.13(.92)$ & .72 & $4.29(.98)$ & .75 \\
\hline
\end{tabular}

The percent change was calculated (t1-t2/t1 X 100) for each facet related to selfawareness (adaptability, relationships, impulse control, and stress management). Scoring increased for each facet item, see Table 3.

Table 3

Percent Change from Pre to Post Assessment $1{ }^{\text {st }}$ Year MOT Students

\begin{tabular}{lccc} 
Trait & Pre-Assessment & Post-Assessment & \% Change \\
\hline \multirow{2}{*}{ Adaptability } & Mean & $\underline{\text { Mean }}$ & \\
Relationships & 4.27 & 6.57 & 7 \\
Impulse Control & 5.79 & 6.00 & 3.6 \\
Stress Management & 4.77 & 5.09 & 6.7 \\
\hline
\end{tabular}

Lastly, in order to answer the research question, is there a difference in trait El skills related to self-awareness between first and second-year MOT students, a t-test was performed to compare pre (beginning of semester) and post-test (end of semester) TEIQue scores (see Table 4). There were no significant differences between groups at the beginning of the semester, so no variables were controlled for the analysis of postsemester data. 
Table 4

Comparison of Post-semester Assessment Data between $1^{\text {st }}$ and $2^{\text {nd }}$ Year MOT Students

\begin{tabular}{lcccc}
\hline Trait & $\begin{array}{l}1^{\text {st }} \text { Year } \\
\text { Students } \\
\text { Mean }\end{array}$ & $\begin{array}{l}2^{\text {nd }} \text { Year } \\
\text { Students } \\
\text { Mean }\end{array}$ & t value & p value \\
\hline Adaptability & 4.57 & 4.12 & -2.42 & $.018^{*}$ \\
Relationships & 6.00 & 5.62 & -2.33 & $.021^{*}$ \\
Impulse Control & 5.09 & 4.89 & -.917 & .33 \\
Stress Management & 4.49 & 4.45 & -.217 & .82 \\
\hline
\end{tabular}

*Indicates significant value

DISCUSSION

The purpose of this study was to describe the impact of using self-reflection journals during the first-year of a MOT program on related trait El scores. The increase in the TEIQue scores in the first-year students indicates that use of self-reflection journals may contribute to improving overall trait El scores. Emotional intelligence and self-awareness skills are critical for the development of positive client-provider relationships and are often predictive of success within one's profession (Romanelli et al., 2006; Slaski \& Cartwright, 2003). Emotional intelligence training has also been shown to lead to improvement in health indicators, well-being and decreased levels of stress (Slaski \& Cartwright, 2003).

The first year MOT students demonstrated an overall increase in the four areas that are addressed using self-reflection journals (Table 4). The students improved in the following trait El areas: adaptability, relationships, impulse control, and stress management. This is important, because, individuals with higher impulse control are more likely to be reflective and less likely to act upon their urges (Petrides, 2009).

Further analysis of the data demonstrated that the facets of relationships and adaptability had a significant increase in scores among the intervention group (Table 4). Higher scores within the relationships facet indicate increased ability to be capable of maintaining fulfilling personal relationships. Also, higher scores within the adaptability facet indicate being flexible and willing to adapt to new conditions (Petrides, 2009). Our findings demonstrate that the use of self-reflection journals has the potential to impact El facets. Prior research has also demonstrated that self-awareness training is proven to be effective and to endure after the initial training is provided (Carvalho et al., 2011; Flowers, Thomas-Squance, Brainin-Rodriguez, \& Yancey, 2014; Hen \& Sharabi-Nov, 2014). The online self-reflection journals allowed students to have time to reflect on personal emotions which may lead to recognition of personal cognitive strategies and emotional responses. 
The findings in this study also align with current perspectives in various healthcare fields, including occupational therapy, regarding the need for El training. El skills are tied to therapeutic use of self in that the emotional skills of therapist inform what the therapist brings to the client-therapist relationship (Andonian, 2017; Carvalho et al., 2011; Romanelli et al., 2006). Increasing self-awareness leads to improved rapport, communication, collaboration, and removes any potential blockages between healthcare providers and clients (Flanagan, 2013; Hall, Roter, Blanch, \& Frankel, 2009; Stoller, Taylor, \& Farver, 2013). Through this study, specific areas of self-awareness that may be impacted by self-reflection journals were identified and include: empathy, emotion expression, emotion perception, and relationships. Improving these specific skills may lead to improved therapeutic rapport for emerging occupational therapy clinicians. Also, curricular changes can be made to address these areas through the creation of self-reflection journals so that occupational therapy students can work to improve these skills as well.

\section{Limitations}

The authors recognize several limitations of the study, including use of a non-equivalent group design, non-randomized, small sample size of students, and data collected from one university, which limits the generalizability of the findings. Also, one group was first year students while the other was second year students. It is possible that the first year students had more potential for growth compared to the second year students. Another limitation is the TEIQue is a self-report tool that measures trait El skills instead of measuring actual El ability. Additionally, multiple comparisons could lead to a false positive. The authors did recognize the possibility of students feeling cohesion due to being in the current occupational therapy program. Therefore, while the researchers are faculty at the university, they were not current instructors the students during the semester of the intervention.

\section{Implications for Occupational Therapy Education}

Published research addressing how to improve overall trait El skills among occupational therapists are limited. While the ability to effectively communicate and work collaboratively with diverse populations is required by Accreditation Council for Occupational Therapy Education, many professional programs do not have specific training targeting self-reflection as a component of how to build strong communication skills (Accreditation Council for Occupational Therapy Education, 2018). This study breaks new ground in several ways, which leaves ample room for future research to probe or refine its findings. First, our results indicate that some trait El abilities may be effectively improved, even using a relatively short intervention. Second, the benefits of self-awareness training may allow our profession to educate more individuals on the value of self-awareness and the impact of El when working with clients. In addition, this intervention provides occupational therapy students with new strategies and tools that can be taught to future clients as well. The study program design and results may contribute to the larger body of knowledge about the impact of self-awareness training and fieldwork performance. As such, this study provides an innovative example of promoting evidence-based, inclusive education within occupational therapy and will assist the profession in expanding its efforts in meeting the American Occupational 
Therapy Association's goals of Vision 2025 (American Occupational Therapy Association, 2017).

\section{Future Research}

This research study was designed to contribute to knowledge as it applies to occupational therapy programs and the impact of self-reflection for occupational therapy students as emerging clinicians. Future research inquiry on program designs, and with a larger sample or longitudinal study, is indicated. Additionally, this study might be conducted on a multi-university level to identify common themes across diverse geographical areas. Furthermore, future research could include examination of how to integrate this training in the occupational therapy curriculum to determine the optimal impact, as well as adding qualitative analysis of students' self-reflection journals.

\section{CONCLUSION}

The purpose of this study was to examine the impact of the use of self-reflection journals on trait El skills. This study's findings add new perspectives and depth to the current research and the evidence supporting the need for El training in occupational therapy curricula. The use of self-reflection journals is one approach that may be used to increase self-awareness and overall El skills. Occupational therapy students that are trained in the use of self-reflection journals could continue to build upon their skills as they move towards becoming emerging clinicians.

The participants' improvement in key areas of trait El components adds important insight to the current body of knowledge regarding how incorporate El training into occupational therapy curricula. Developing training that encourages more opportunities for self-reflection provides students with a chance to practice and develop new cognitive strategies and emotional responses. Occupational therapy educators, supervisors and employers need to encourage students to practice self-reflection skills and allow time for students to process this competency.

\section{References}

Accreditation Council for Occupational Therapy Education [ACOTE]. (2018).

Accreditation Council for Occupational Therapy Education Standards. American Journal of Occupational Therapy, 66(6_Supplement), S6-S74. https://doi.org/10.5014/ajot.2012.66S6

Allen, A., Montgomery, M., Tubman, J., Frazier, L., \& Escovar, L. (2003). The effects of assessment feedback on rapport-building and self enhancement processes. Journal of Mental Health Counseling, 25(3), 165-182. https://doi.org/10.17744/mehc.25.3.Iw7h84q861dw6yti

Allen, A., Montgomery, M., Tubman, J., Frazier, L., \& Escovar, L. (2003). The effects of assessment feedback on rapport-building and self enhancement processes. Journal of Mental Health Counseling, 25(3), 165-182. https://doi.org/10.17744/mehc.25.3.Iw7h84q861dw6yti

American Occupational Therapy Association. (2017). Vision 2025. American Journal of Occupational Therapy, 71, 7103420010p1. https://doi.org/10.5014/ajot.2017.713002 
Andonian, L. (2017). Emotional intelligence: An opportunity for occupational therapy. Occupational Therapy in Mental Health, 1-9. ttps://doi.org/10.1080/0164212X.2017.1328649

Besika, A., Collard, P., \& Coogan, J. (2018). Attitudes of therapists towards people with learning disabilities. Counseling \& Psychotherapy Research, 18(1), 89-101. https://doi-org/ezproxy.bu.edu/10.1002/capr.12139

Blanco, E., Garcia, L., \& Aluja, A. (2016). The location of the Trait Emotional Intelligence in the Zuckerman's Personality Model space and the role of General Intelligence and social status. Scandinavian Journal of Psychology, 57(5), 453-463. https://doi.org/10.1111/sjop.12307

Bonvicini, K., Perlin, M., Bylund, C., Carroll, G., Rouse, R., \& Goldstein, M. (2009). Impact of communication training on physician expression of empathy in patient encounters. Patient Education and Counseling, 75(1), 3-10. https://doi.org/10.1016/j.pec.2008.09.007

Brown, T., Williams, B., \& Etherington, J. (2016). Emotional intelligence and personality traits as predictors of occupational therapy students' practice education performance: A cross-sectional study. Occupational Therapy International, 23(4), 412-424. https://doi.org/10.1002/oti.1443

Carmeli, A. J. (2006). The relationship among emotional intelligence, task performance, and organizational citizenship behaviors. Human Performance, 19(4), 403-419. https://doi.org/10.1207/s15327043hup1904 5

Carvalho, I., Pais, V., Almeida, S., Ribeiro-Silvia, R., Figueiredo-Braga, M., Teles, A., . . . Mota-Cardosa, R. (2011). Learning clinical communication skills: Outcomes of a program for professional practitioners. Patient Education and Counseling, 84(1), 84-89. https://doi.org/10.1016/j.pec.2010.05.010

Cole, M., \& McLean, V. (2003). Therapeutic relationships re-defined. Occupational Therapy in Mental Health, 19(2), 33-56. https://doi.org/10.1300/J004v19n02 03

Duval, S., \& Wicklunds, R. (1972). A theory of objective self-awareness. New York: Academic Press.

Flanagan, J. (2013, August). Self-awareness. Retrieved from Trainingjournal.com: www.trainingjournal.com

Flowers, L., Thomas-Squance, R., Brainin-Rodriguez, J., \& Yancey, A. (2014). Interprofessional social and emotional intelligence skills training: Study findings and key lessons. Journal of Interprofessional Care, 28(2), 157-159. https://doi.org/10.3109/13561820.2013.847407

Goleman, D. (2006). Emotional Intelligence. New York: Bantam Dell.

Hall, J. A., Roter, D., Blanch, D., \& Frankel, R. (2009). Observer-rated rapport in interactions between medical students and standardized patients. Patient Education and Counseling, 76(3), 323-327. https://doi.org/10.1016/i.pec.2009.05.009

Hen, M., \& Sharabi-Nov, A. (2014). Teaching the teachers: Emotional intelligence training for teachers. Teaching Education, 25(4), 375-390. https://doi.org/10.1080/10476210.2014.908838

Johnson, D. (2015). Emotional intelligence as a crucial component to medical education. Internation Journal of Medical Education, 6, 179-183. https://doi.org/10.5116/ijme.5654.3044 
Kron, F., Fetters, M., Scerbo, M. W., White, C., Lypson, M., Padilla, M., ... Becker, D. (2016). Using a computer simulation for teaching communication skills: A blinded multisite mixed methods randomized controlled trial. Patient Education and Counseling, 100(4), 748-759. https://doi.org/10.1016/i.pec.2016.10.024

MacCann, C., Joseph, D., Newman, D., \& Roberts, R. (2014). Emotional intelligence is a second-stratum factor of intelligence: Evidence from hierarchical and bifactor models. Emotion, 14(2), 358-374. https://doi.org/10.1037/a0034755

Mayer, J. S. (2008). Emotional intelligence: New ability or eclectic traits? American Psychologist, 63(6). 503-517. https://doi.org/10.1037/0003-066X.63.6.503

McKenna, J., \& Mellson, J. (2013). Emotional intelligence and the occupational therapist. British Journal of Occupational Therapy, 76(9), 427-430. https://doi.org/10.4276/030802213X13782044946382

Osif, B. A. (2010). Communication. Chicago, IL, USA.

Patterson, P. (2016). Retrospective: Tracking the impact of communications effectiveness on client satisfaction, trust and loyalty in professional services. The Journal of Services Marketing, 30(5), 485-489. https://doi.org/10.1108/JSM-052016-0190

Petrides, K. (2009). Psychometric properties of the Trait Emotional Intelligence Questionnaire. In C. Stough, D. Saklofske, \& J. Parker, Advances in the assessment of emotional intelligence. New York: Srpinger. https://doi.org/10.1007/978-0-387-88370-0 5

Petrides, K. (2018, May 15). London Psychometric Laboratory. Retrieved from Psychometric Lab: www.psychometriclab.com

Romanelli, F., Cain, J., \& Smith, K. (2006). Emotional intelligence as a predictor of academic and/or professional success. American Journal of Pharmaceutical Education, 70(3), 1-10. https://doi.org/10.5688/aj700369

Slaski, M., \& Cartwright, S. (2003). Emotional intelligence training and its implications fo stress, health and performance. Stress and Health, 19(4), 233-239. https://doi.org/10.1002/smi.979

Stoller, J., Taylor, C., \& Farver, C. (2013). Emotional intelligence competencies provide a developmental curriculum for medical training. Medical Teacher, 35(3), 243247. https://doi.org/10.3109/0142159X.2012.737964

Zeidner, M., Matthews, G., \& Roberts, R. (2009). What we know about emotional intelligence: How it affects learning, work, relationships, and our mental health. Cambridge: MIT Press. https://doi.org/10.7551/mitpress/7404.001.0001 